\title{
Direct electric curing of alkali-activated fly ash concretes: A tool for wider utilization of
}

\section{fly ashes}

\author{
Maxim Kovtun $^{\mathrm{a} *}$, Mateusz Ziolkowski ${ }^{\mathrm{a}}$, Julia Shekhovtsova ${ }^{\mathrm{a}}$, Elsabe Kearsley ${ }^{\mathrm{a}}$ \\ ${ }^{a}$ Department of Civil Engineering, University of Pretoria, Pretoria, 0002 South Africa \\ max.kovtun@up.ac.za (M Kovtun) \\ mateusz.zski@gmail.com (M Ziolkowski)
}

j.shekhovtsova@gmail.com (J Shekhovtsova)

elsabe.kearsley@up.ac.za (E Kearsley)

*Corresponding author at: Department of Civil Engineering, University of Pretoria, Pretoria, 0002 South Africa. Tel.: +27 12420 6953. E-mail address: max.kovtun@up.ac.za (M Kovtun)

\begin{abstract}
Utilization of the fly ashes is a major problem in many developing countries and in South Africa only about $7 \%$ of the fly ash produced annually by coal-fired power stations, has being utilized. Although, fly ashes can be used as an alternative binder in alkali-activated concretes, strength development of these concretes at room temperature is slow limiting application of the material. Direct electric curing is proposed for heat curing of alkali-activated fly ash concrete which will open new opportunities for in-situ applications of these concretes in the construction industry thus increasing the amount of beneficially utilized fly ash. Alkaliactivated fly ash concretes containing unclassified low calcium fly ash, sodium hydroxide and sodium silicate solutions were cured at $60{ }^{\circ} \mathrm{C}$ by means of direct electric curing. The electric resistivity and compressive strength development of the concretes were investigated. The resistivity strongly depends on the type of activator used. Compressive strength up to 33.8 MPa and 48.5 MPa at 2 and 28 days respectively, can be achieved after a short period of
\end{abstract}


direct electric curing. This opens new opportunities for wider application of alkali-activated fly ash concretes and for more extensive utilization of fly ash.

Keywords: Alkali-Activated Concrete; Fly Ash; Electric Resistivity; Compressive Strength; Direct Electric Curing. 


\section{Introduction}

In many developing countries, electricity is generated by coal-fired power plants producing significant amounts of fly ash. Utilization of the fly ash is a major problem which needs a solution. In South Africa more that 40 million tonnes of ash is produced annually. Sasol (an international integrated energy and chemicals company) produces about 8 million tonnes of gasification ash per year (Matjie et al., 2005), while Eskom (the largest power utility in Africa) produces in excess of 30 million tonnes of fly ash annually. Only about $7 \%$ of all fly ash produced by Eskom is beneficially used and millions of tonnes of ash are being stored and disposed in ash dams and landfill sites annually (Eskom Integrated Report, 2014).

On the other hand, the increasing awareness of the environmental impact of Portland cement production has driven an intensive search for alternative binding systems for concrete. Alkaliactivated cements are amongst the most researched binders, attracting increasing interest for their potential to enable the construction industry to operate within the limitations placed on $\mathrm{CO}_{2}$ emissions (Kajaste and Hurme, 2016). According to Yang et al. (2013), the reduction rate for the $\mathrm{CO}_{2}$ emissions of alkali-activated cement concrete relative to ordinary Portland cement concrete commonly ranges between 55 and 75\%, while according to van Deventer et al. (2010) the reduction can be as big as $80 \%$. Heath et al. (2014) believe that the use of multiple initial aluminosilicate sources and complex mix design of alkali-activated materials has the potential to reduce the global warming effect compared to Portland cement. Alkaliactivated cements utilize different raw materials including fly ashes (Torres-Carrasco and Puertas, 2015), slags (Abdalqader et al., 2015), kaolin (Longhi et al., 2015), rice husk ash and different soils(He et al., 2013; Mejía et al., 2016; Nimwinya et al., 2016). Alkali-activated cements based on fly ash probably have the greatest opportunity for commercial utilisation due to the worldwide presence of coal-fired power plants, as well as the more favourable rheological properties and lower water demand when compared to mixes based on calcined clays (van Deventer et al., 2012). McLellan et al. (2011) emphasised that the Australian 
alkali-activated fly ash (AAFA) cements can provide an estimated 44-64\% reduction in the $\mathrm{CO}_{2}$ emissions over ordinary Portland cement. Therefore, a large amount of fly ash, disposed in ash dams and landfills at the moment, could be beneficially utilized in alkali-activated cements.

There are however a few obstacles preventing the adoption of AAFA cements, which include the variability in the chemical and mineralogical composition of fly ashes (FernándezJiménez and Palomo, 2003), and, despite the fact that the alkali activation of fly ash is an exothermic reaction (Palomo et al., 1999), slow strength development at ambient temperatures (Puertas et al., 2000; Somna et al., 2011). Dry or steam heat curing in a wide range of temperatures is normally used to accelerate the alkali activation process in order to obtain an adequate early age compressive strength for AAFA cements and concretes (Bakharev, 2005; Kovalchuk et al., 2007). Although energy sources like microwave and solar radiation have been used for curing AAFA cements and mortars. Somaratna et al. (2010) showed that volumetric heating provided by microwave curing results in faster property development of $\mathrm{NaOH}$ activated fly ash mortars as compared to conventional heat curing. Chindaprasirt et al. (2013) also confirmed that short microwave curing accelerates reaction in AAFA cement resulting in improved compressive strength. Diop and Grutzeck (2008) showed that solar radiation can be used to produce bricks made of alkali-activated material. Microwave and sun curing are promising techniques but they are rather energy or time consuming respectively and, in case of microwave curing, are difficult to implement for big structural elements on a construction site.

Efficient heat curing of AAFA concrete on construction sites would open new opportunities for in-situ application of the material resulting in increased utilization of fly ash. Externally applied heat curing techniques such as steam curing, autoclaving, etc. are not easy to implement on construction sites. However, most construction sites have electric power supply which can be used for direct electric curing (DEC) of concrete when an alternating electric 
current is passed through the fresh concrete to accelerate the curing process by means of direct ohmic heating (Bredenkamp et al., 1993; Heritage et al., 2000). Direct electric curing can be energy efficient, with less initial capital investment and lower running cost than that required for externally applied heat curing (steam, autoclave, etc.) (Wadhwa et al., 1987). Portland cement concretes can gain as much as 60 to $70 \%$ of the 28-d strength in 24 hours when cured by means of direct electric current Wadhwa et al. (1987) reported. Heritage et al. (2000) found that electrically cured Portland cement concretes can also achieve higher compressive strengths than that of concretes cured normally. Portland cement concretes have been cured for decades by means of DEC but very limited information could be found on DEC of alkali-activated concretes (Kovtun et al., 2015).

This paper provides information on the response of AAFA concretes to DEC. The main objectives of the study include investigating electric resistivity, temperature coefficient and compressive strength development of AAFA concrete cured by means of DEC. The influence of type and concentration of activator, as well as duration of pre- and isothermal curing on the electric and mechanical properties of AAFA concretes was studied. It is believed that DEC is an effective curing method which can be applied to in-situ AAFA concrete structures resulting in more extensive utilization of fly ash in the construction industry.

\section{Materials and methods}

\subsection{Materials}

The chemical and mineralogical composition of the unclassified low calcium fly ash used in this investigation is presented in Table 1 and Table 2 respectively. The amount of amorphous $\mathrm{SiO}_{2}$ and $\mathrm{Al}_{2} \mathrm{O}_{3}$, found by deduction of the oxide contents in the crystalline phases of fly ash from its chemical composition (Fernández-Jiménez et al., 2006a; Ward and French, 2006), 
are shown in Table 2. The particle size distribution is presented in Fig. 1. The specific gravity and Blaine fineness of the fly ash were $2240 \mathrm{~kg} / \mathrm{m}^{3}$ and $240 \mathrm{~m}^{2} / \mathrm{kg}$ respectively.

\section{Table 1}

Chemical composition of fly ash.

\begin{tabular}{ccccccccccc}
\hline $\mathrm{SiO}_{2}$ & $\mathrm{Al}_{2} \mathrm{O}_{3}$ & $\mathrm{CaO}$ & $\mathrm{Fe}_{2} \mathrm{O}_{3}$ & $\mathrm{TiO}_{2}$ & $\mathrm{~K}_{2} \mathrm{O}$ & $\mathrm{MgO}$ & $\mathrm{P}_{2} \mathrm{O}_{3}$ & $\mathrm{SO}_{3}$ & Other & LOI \\
55.1 & 32.2 & 4.5 & 3.6 & 1.5 & 0.8 & 0.8 & 0.3 & 0.1 & 1.2 & 0.7
\end{tabular}

Table 2

Mineralogical composition and amorphous silica and alumina content of the fly ash.

\begin{tabular}{cccccc}
\hline Hematite & Mullite $^{\mathrm{a}}$ & Quartz & Amorphous & $\mathrm{Al}_{2} \mathrm{O}_{3}$ amoph & $\mathrm{SiO}_{2}$ amorph \\
0.9 & 25.8 & 11.6 & 61.7 & 13.5 & 36.4
\end{tabular}

a - powder diffraction file \# 01-083-1881

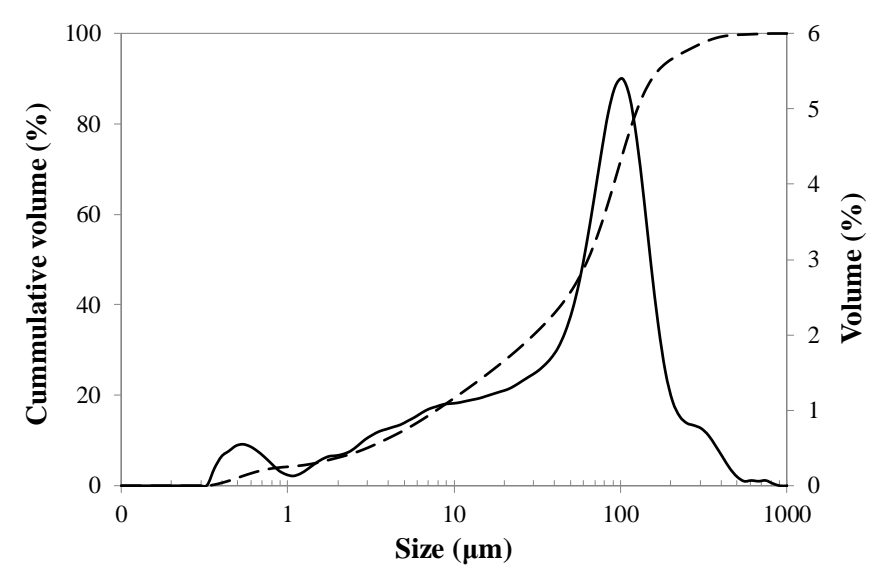

Fig. 1. Particle size distribution of the fly ash.

The suitability of fly ash as aluminosilicate source for the production of alkali-activated materials depends on its characteristics, including particle size, amorphous phase, $\mathrm{Fe}_{2} \mathrm{O}_{3}$, $\mathrm{CaO}$, reactive silica and alumina, and unburned material content (Diaz et al., 2010; Fernández-Jiménez and Palomo, 2003). Most of the characteristics of the fly ash are within the limits proposed by Fernández-Jiménez and Palomo (2003), but the particle size 
distribution is too coarse, with about $60 \%$ particles greater than $45 \mu \mathrm{m}$ (Fig. 1). The relatively low content of amorphous alumina (13.5\%) and silica (36.4\%) in the fly ash composition must be noted (Table 2). Fernández-Jiménez and Palomo (2003) emphasised that the amorphous silica content of fly ash should be between $40-50 \%$. Two fly ashes investigated by Fernández-Jiménez et al. (2006b) had 14.1\% and 20.5\% of amorphous alumina, and the fly ash with lower amorphous alumina was less reactive. Therefore the reactivity of the Lethabo fly ash used in this study may be relatively low. To increase the reactivity of fly ash, beneficiation by different methods has been used in previous studies. Somna et al. (2011) showed that milling of fly ash significantly increased compressive strength of $\mathrm{NaOH}$ activated fly ash pastes cured at ambient temperature. The primary cause of the observed strength gain was the increased reactivity arising from the increased surface area of the milled fly ash. Van Riessen and Chen-Tan (2013a, 2013b) found that sieving, milling and magnetic separation increased the fraction of reactive amorphous material. The improved fly ash homogeneity and reactivity increased compressive strength of alkali-activated fly ash pastes by up to $32 \%$. In this research, unclassified fly ash was purposely used as it would simplify the production process of alkali-activated materials (no beneficiation is needed) thus increasing the amount of beneficially utilized fly ash.

Commercially available sodium hydroxide flakes (98.0\% purity), liquid sodium silicate (15.0\% $\mathrm{Na}_{2} \mathrm{O}, 29.5 \% \mathrm{SiO}_{2}, 55.5 \% \mathrm{H}_{2} \mathrm{O}$ ) and tap water were used to prepare the activator solutions.

Crushed dolomite stone $(9.5 \mathrm{~mm})$ and dolomite sand with a fineness modulus of 3.86 and 9\% passing the $75 \mu \mathrm{m}$ sieve were used as the coarse and fine aggregates respectively. The specific gravity of the aggregates was $2860 \mathrm{~kg} / \mathrm{m}^{3}$.

\subsection{Mix design and preparation of AAFA concretes}


The mix design of AAFA concretes was based on the findings of Ravikumar et al. (2010) indicating that there is an optimal fly ash content of $18 \%$ by volume (equivalent to 400 $\mathrm{kg} / \mathrm{m}^{3}$ ), resulting in the highest compressive strength for AAFA concrete. In this investigation, mixes activated with sodium hydroxide and sodium silicate solutions, had an activator concentration equivalent of $9 \% \mathrm{Na}_{2} \mathrm{O}$ per fly ash mass. The activator concentration was chosen based on the results of previous work of Shekhovtsova et al. (2014) which utilized classified fly ash from the same power station. To investigate the influence of activator concentration on properties of AAFA concrete subjected to DEC, the amount of activator was varied for mixes activated with a combination of sodium hydroxide and sodium silicate (Table 3). The molar silicate modulus (Ms) of the combined activator was set at 1.25 (Hardjito and Rangan, 2005). A water-to-binder solids (where water is all water used in an activator solution; binder solids are fly ash and solids of activator, i.e. $\mathrm{Na}_{2} \mathrm{O}$ and $\mathrm{SiO}_{2}$ ) ratio of 0.35 was used for mixes activated with only sodium silicate (LSS-9, Table 3) or sodium hydroxide (SH-9, Table 3), and 0.4 for mixes contained the combined activator (LSS-SH mixes, Table 3). The sand to total aggregate ratio was kept constant at 0.35 by weight in all mixes.

\section{Table 3}

Mix designs of AAFA concrete.

\begin{tabular}{lccccc}
\hline \multicolumn{1}{c}{ Mix } & Activator & $\mathrm{Na}_{2} \mathrm{O}_{\mathrm{eq}}, \mathrm{wt}$ \% & $\mathrm{Ms}$ & Water/binder solids ratio & Sand/aggregate ratio \\
\hline LSS-9 & $\mathrm{Na}_{2} \mathrm{SiO}_{3}$ & 9 & 2.0 & 0.35 & 0.35 \\
SH-9 & $\mathrm{NaOH}$ & 9 & & 0.35 & 0.35 \\
LSS-SH-8 & $\mathrm{Na}_{2} \mathrm{SiO}_{3}+\mathrm{NaOH}$ & 8 & 1.25 & 0.40 & 0.35 \\
LSS-SH-10 & $\mathrm{Na}_{2} \mathrm{SiO}_{3}+\mathrm{NaOH}$ & 10 & 1.25 & 0.40 & 0.35 \\
LSS-SH-12 & $\mathrm{Na}_{2} \mathrm{SiO}_{3}+\mathrm{NaOH}$ & 12 & 1.25 & 0.40 & 0.35 \\
\hline
\end{tabular}


The activator solutions were prepared and cooled down to room temperature before being added to the concrete in a pan mixer. The concrete mix was placed into modified casting moulds and vibrated for 1 minute.

\subsection{Experimental set up}

The layout of the rig used for direct electric curing of AAFA concrete in this study is presented in Fig. 2. The rig consisted of modified moulds, a power supply with capacity 300 VA, maximum current $12 \mathrm{~A}$ and output voltage 0-260 V, a temperature controller, a digital ammeter and a digital voltmeter (Heritage et al., 2000).

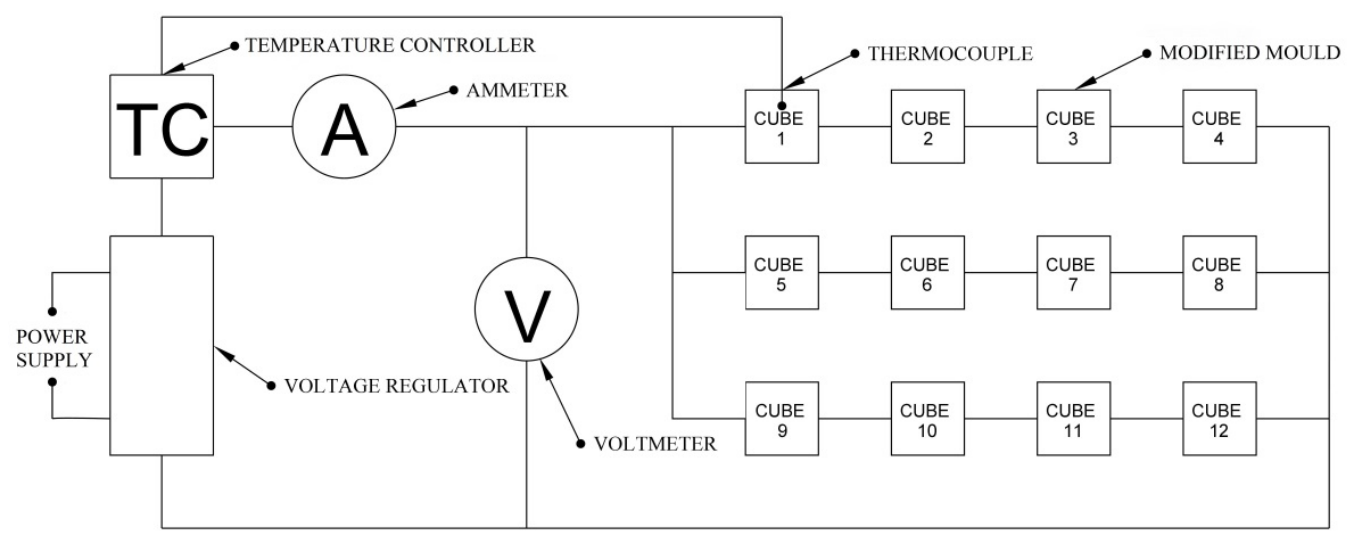

Fig. 2. Layout of the DEC rig.

The modified moulds $(100 \times 100 \times 100 \mathrm{~mm})$ were placed in a $50 \mathrm{~mm}$ thick polystyrene shell to limit energy loss, and these moulds were kept in a fully closed containment box for safety during the DEC process. The lid of the containment box consisted of a $50 \mathrm{~mm}$ thick polystyrene plate which sealed the moulds to prevent extensive moisture loss during the curing process. Criado et al. (2010) and Kovalchuk et al. (2007) showed that moisture retention during heat treatment of AAFA cements is very important for microstructure and strength development. Prevention of extensive evaporation is also crucial for DEC (Heritage et al., 2000; Whittington et al., 1981). Three rows of the modified moulds (each consisting of 
4 moulds connected in series) were connected in parallel (Fig. 2). The modified moulds are removable for ease of casting fresh concrete. The modified moulds were constructed in such a way (Fig. 3) that the electric current traverses the full area of the specimen (Whittington et al., 1981) ensuring an equal electric field throughout the specimen. To eliminate the possibility of a short circuit while obtaining the true temperature readings of the concrete mix, a thermocouple with mineral insulation was placed in the centre of one of the moulds as shown in Fig. 3. Special care was taken of the mould that contained the thermocouple, to ensure that the thermocouple was properly covered by the mix.

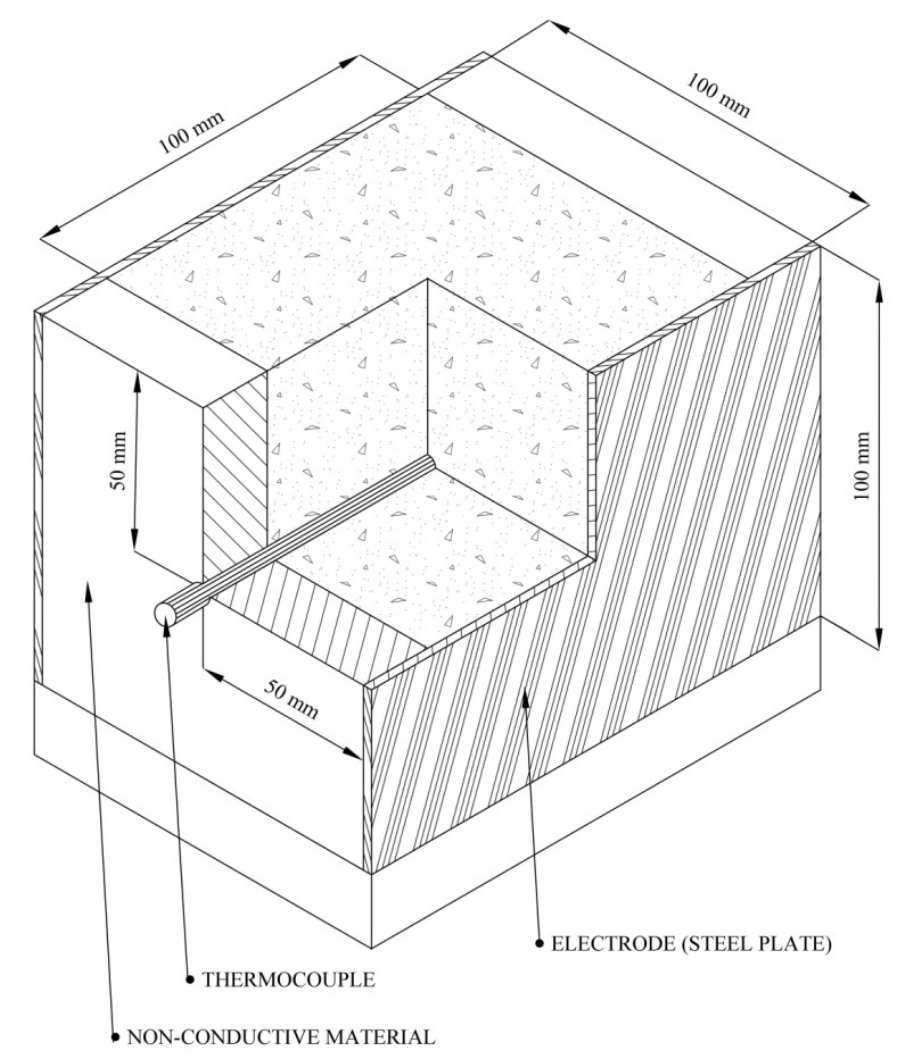

Fig. 3. Modified mould with thermocouple.

\subsection{Experimental procedures}

All mixes were cured following temperature cycle (Neville, 1995; Wilson and Gupta, 2004) consisting of precuring, heating, isothermal and natural cooling phases (Table 4). 
During the first stage of the experiment, the mixes activated with sodium hydroxide ( $\mathrm{SH}-9$, Table 3) and sodium silicate (LSS-9, Table 3) solutions were precured for different times to investigate the effect of duration of precuring on strength development of AAFA concrete. The duration of the isothermal phase was kept constant at 6 hours (Table 4) which was chosen from a practical point of view as DEC could be done on a construction site during the off-peak hours at night.

\section{Table 4}

Curing regimes.

\begin{tabular}{ccccccc}
\hline Stage & Mix & \multicolumn{3}{c}{ Precuring at $25{ }^{\circ} \mathrm{C}(\mathrm{h})$} & \multicolumn{2}{c}{ Isothermal curing at $60^{\circ} \mathrm{C}(\mathrm{h})$} \\
\cline { 3 - 7 } & & 2 & 12 & 24 & 3 & 6 \\
\hline \multirow{2}{*}{ I } & LSS-9 & $\sqrt{ }$ & $\sqrt{ }$ & $\sqrt{ }$ & & $\sqrt{ }$ \\
& SH-9 & $\sqrt{ }$ & $\sqrt{ }$ & $\sqrt{ }$ & & $\sqrt{ }$ \\
\hline & LSS-SH-8 & $\sqrt{ }$ & & $\sqrt{ }$ & $\sqrt{ }$ \\
II & LSS-SH-10 & $\sqrt{ }$ & & $\sqrt{ }$ & $\sqrt{ }$
\end{tabular}

During the second stage, a precuring phase of 2 hours was chosen for the mixes containing the combined activator (LSS-SH, Table 3). The duration of isothermal curing was varied (Table 4) to determine if AAFA concrete with reasonable strength could be developed using short curing times.

All concrete mixes were heated at a rate of $20 \pm 0.5{ }^{\circ} \mathrm{C} / \mathrm{h}$ to avoid rapid thermal expansion which could disrupt concrete structure (Wilson and Gupta, 2004). The temperature of the isothermal phase was set at $60{ }^{\circ} \mathrm{C}$. Previous research on DEC of Portland cement concrete showed that isothermal curing at $60{ }^{\circ} \mathrm{C}$ gave higher compressive strength at 28 days in comparison to $80{ }^{\circ} \mathrm{C}$ (Heritage et al., 2000). Similar conclusion can be drawn from the study done by Shekhovtsova et al. (2014) on alkali activation of fly ash where heat curing at $60{ }^{\circ} \mathrm{C}$ 
provided the best compressive strength in the long term. For practical application, the temperature of isothermal curing of in-situ concrete structures is normally limited to $60{ }^{\circ} \mathrm{C}$ thus avoiding crazing of concrete surface. After the isothermal phase, the DEC rig was switched off, and concrete specimens were left to cool down naturally within the containment box. Once the specimens were cooled to $30^{\circ} \mathrm{C}$, they were de-moulded and stored in a fog room at $>95 \%$ relative humidity and $25 \pm 1{ }^{\circ} \mathrm{C}$ until testing. A set of three concrete specimens was tested at 2, 7 and 28 days according to BS EN 12390-3 (2009).

The resistivity, $\rho$, of AAFA concrete mixes was calculated using Ohm's law as indicated in Equation 1.

$\rho_{c}=R \cdot A / L$

Where $\rho_{c}-$ resistivity of concrete, $\Omega \cdot \mathrm{m}$;

$R$ - resistance of a concrete sample, $\Omega$;

$L$ - length of a concrete sample, m;

$A$ - cross-sectional area of a concrete sample, $\mathrm{m}^{2}$.

Calculation of resistivity of AAFA cement paste was done according to the formula of Whittington et al. (1981) for Portland cement pastes. The formula was modified as indicated in Equation 2 to 4 to take into account the coarse porosity caused by incomplete compaction of the concrete mix.

$F=1.04((1-\text { Por }) \varphi)^{-1.20}$

Where $F$ - formation factor;

Por - porosity of AAFA concrete samples at 1 day (measured by hydrostatic weighing as indicated in Equation 3);

$\varphi$ - theoretical fractional volume of AAFA cement paste in concrete mix.

Por $=1-m /\left(m-m_{w}\right) / \gamma$

Where $m$ - mass of concrete sample, kg;

$m_{w}$ - mass of concrete sample in water (hydrostatic weight), kg; 
$r$ - theoretical relative density of AAFA concrete.

$F=\rho_{c} / \rho_{p}$

Where $\rho_{p}$ - resistivity of AAFA cement paste, $\Omega \cdot \mathrm{m}$.

The temperature coefficient of resistivity was found from the following formula (Whittington et al., 1981):

$\rho_{p 2}=\rho_{p 1} /\left(1+\alpha\left(T_{2}-T_{1}\right)\right)$

Where $\rho_{p 1}, \rho_{p 2}$ - resistivity of AAFA cement paste at temperature $T_{1}$ and $T_{2}$ respectively,

$\Omega \cdot \mathrm{m} ;$

$T_{1}, T_{2}$ - temperature of AAFA concrete mix, ${ }^{\circ} \mathrm{C}$;

$\alpha$ - temperature coefficient of resistivity, ${ }^{\circ} \mathrm{C}^{-1}$.

\section{Results and discussion}

\subsection{General observations}

Thermal expansion of the plastic parts of the modified moulds during the heating phase resulted in an air gap between the electrodes and samples. The air gap broke the electric circuit, effectively discontinuing DEC. This was only the case for the concrete mix activated with sodium hydroxide (SH-9, Table 3). The SH-9 mix precured for 12 and 24 hours did therefore not reach the target temperature of $60^{\circ} \mathrm{C}$ (Fig. 4). The concrete mixes containing sodium silicates (LSS-9, LSS-SH, Table 3) did not lose contact with the electrodes due to higher adhesion of the mixes to metal surfaces. 


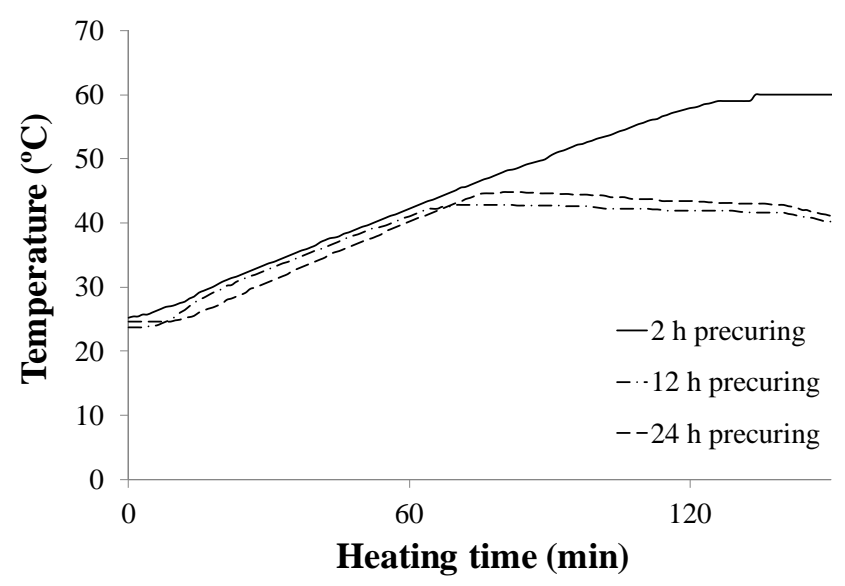

Fig. 4. Temperature profile of SH-9 mix during the heating phase.

It is also important to note that the SH-9 mix displayed intensive efflorescence formation after curing in the fog room. Shekhovtsova et al. (2014) observed intensive efflorescence formation on samples of AAFA cement pastes activated with sodium hydroxide at $9 \% \mathrm{Na}_{2} \mathrm{O}_{\text {eq }}$ when cured at ambient temperature, while curing at $60{ }^{\circ} \mathrm{C}$ resulted in no efflorescence formation. The efflorescence formation observed in this study thus indicates insufficient heat curing of the SH-9 mix caused by the air gap formed between the electrodes and the sample during the heating phase. The concrete samples were cooling instead of being isothermally cured.

\subsection{Electric properties}

Electric resistivity of concrete is one of the main parameters to design equipment used for DEC of a specific concrete structure. The resistivity of all AAFA cement pastes and concretes during the heating phase, calculated using Equation 4 and 1 respectively, is presented in Table 5.

The electric properties of concrete are governed by the properties of the cement paste (Whittington et al., 1981). It can be seen that the resistivity of AAFA cement pastes containing sodium silicate (LSS-9, LSS-SH, Table 5) was not influenced by the duration of precuring, but the resistance of the paste containing sodium hydroxide as a sole activator (SH- 
9, Table 5) doubled when precuring was longer than 2 hours. The increase in the resistivity will have a negative effect on power consumption during DEC as can be seen from Joule's law (Equation 6):

$Q=I^{2} R t=U^{2} t / R$

Where $Q$ - heat generated, J;

$$
\begin{aligned}
& I \text { - electric current, Amp; } \\
& R \text { - electric resistance, } \Omega ; \\
& U \text { - potential, } \mathrm{V} ; \\
& t \text { - time, s. }
\end{aligned}
$$

Hence it can be suggested that AAFA concrete containing sodium hydroxide as a sole

\begin{tabular}{|c|c|c|c|c|c|c|c|c|c|}
\hline Mix & $\begin{array}{l}\text { Precuring } \\
\text { (h) }\end{array}$ & Por & $\begin{array}{l}\text { Fractional } \\
\text { volume, } \varphi\end{array}$ & $\rho_{c 1}(\Omega \cdot \mathrm{m})^{\mathrm{a}}$ & $\rho_{c 2}(\Omega \cdot \mathrm{m})^{\mathrm{b}}$ & $\begin{array}{c}\text { Formation } \\
\text { factor, } F\end{array}$ & $\rho_{p 1}(\Omega \cdot \mathrm{m})^{\mathrm{a}}$ & $\rho_{p 2}(\Omega \cdot \mathrm{m})^{\mathrm{b}}$ & $\alpha,\left({ }^{\circ} \mathrm{C}^{-1}\right)$ \\
\hline LSS-9 & 2 & 0.035 & 0.311 & 8.85 & 2.12 & 4.41 & 2.01 & 0.48 & 0.081 \\
\hline LSS-9 & 12 & 0.034 & 0.311 & 8.02 & 2.23 & 4.40 & 1.82 & 0.51 & 0.072 \\
\hline LSS-9 & 24 & 0.028 & 0.311 & 8.27 & 2.23 & 4.37 & 1.89 & 0.51 & 0.078 \\
\hline SH-9 & 2 & 0.043 & 0.342 & 1.00 & 0.63 & 3.97 & 0.25 & 0.16 & 0.030 \\
\hline SH-9 & 12 & 0.025 & 0.342 & 2.21 & 1.50 & 3.88 & 0.57 & 0.39 & 0.034 \\
\hline SH-9 & 24 & 0.025 & 0.342 & 1.77 & 1.23 & 3.88 & 0.46 & 0.32 & 0.031 \\
\hline LSS-SH-8 & 2 & 0.020 & 0.351 & 3.68 & 1.16 & 3.74 & 0.98 & 0.31 & 0.056 \\
\hline LSS-SH-10 & 2 & 0.020 & 0.360 & 4.43 & 1.16 & 3.63 & 1.22 & 0.32 & 0.074 \\
\hline LSS-SH-12 & 2 & 0.018 & 0.369 & 6.85 & 1.30 & 3.52 & 1.95 & 0.37 & 0.119 \\
\hline
\end{tabular}
activator should not be precured for long times.

\section{Table 5}

Physical and electric properties of AAFA cement pastes and concretes. 
The second important observation is that the resistivity of the AAFA cement pastes strongly depends on the type of activator used (Table 5). Sodium hydroxide gives the lowest resistivity (SH-9) followed by the combined activator (LSS-SH) and sodium silicate (LSS-9). The resistivity of LSS-SH cement pastes is lower than the resistivity of the LSS-9 cement paste despite a significantly higher water-to-binder solids ratio of the former (Table 3). The decrease in resistivity could be influenced by two factors. Firstly, the addition of sodium hydroxide to sodium silicate in the combined activator increased concentration of sodium ions in LSS-SH cement pastes. The increase in concentration of sodium ions is related to the decreased silica modulus of the combined activator (Ms=1.25 in comparison to Ms=2.0 for pure sodium silicate solution). Therefore, a decrease in the resistivity of AAFA cement paste can be expected with a decrease in silica modulus of sodium silicate activator. Secondly, LSS-SH cement pastes have higher volumes of alkaline solution in their composition in comparison to LSS-9 cement paste.

It is important to note that the resistivity of AAFA cement pastes (Table 5) is generally lower in comparison to Portland cement paste with water/cement ratio of 0.40 studied by Whittington et al. (1981) which had the resistivity of $2.2 \Omega \cdot \mathrm{m}$. The DEC power consumption of AAFA concretes can thus be lower in comparison to Portland cement concretes. The change in the resistivity of AAFA concretes during the heating phase is presented in Fig. 5.

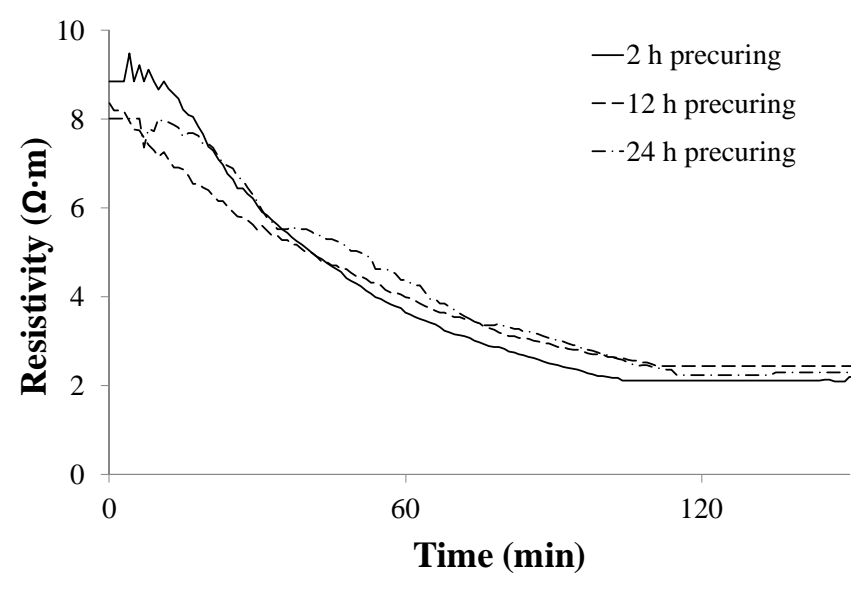


a) LSS-9

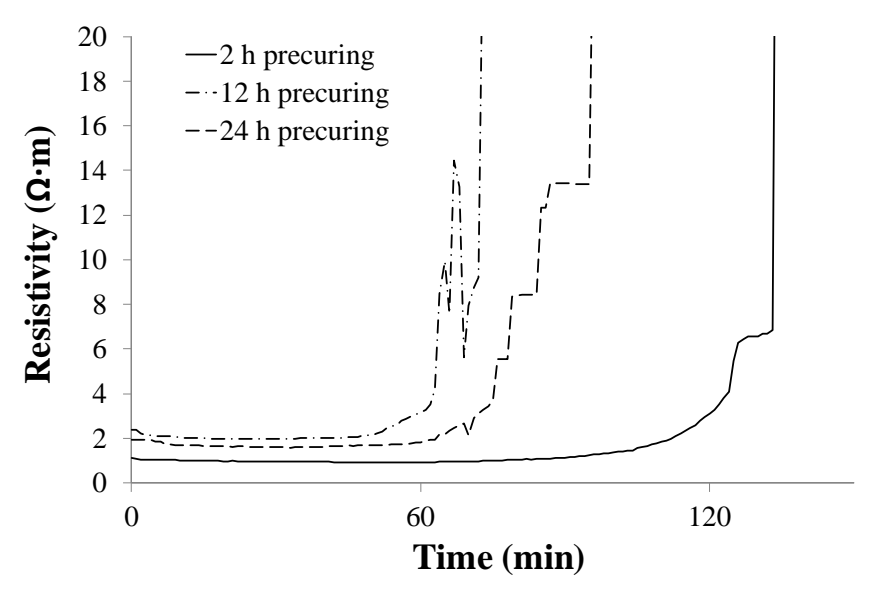

b) $\mathrm{SH}-9$

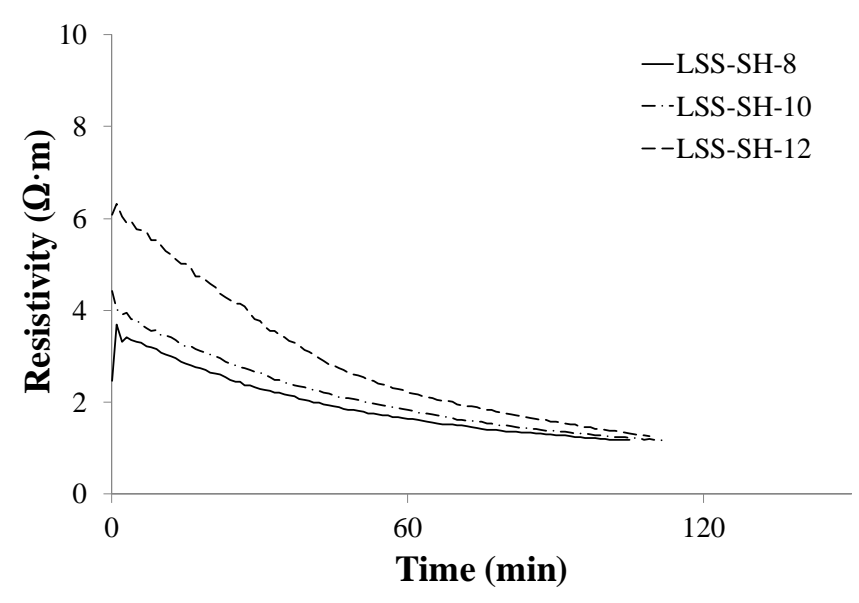

c) LSS-SH

Fig. 5. Development of the resistivity of AAFA concrete mixes during the heating phase.

The decrease in the resistivity of AAFA concretes with increase in temperature correlates with the behaviour of Portland cement concretes (Bredenkamp et al., 1993; Whittington et al., 1981). A sudden increase in the resistivity when SH-9 mix was cured (Fig. 5,b) is attributed to the development of an air gap between the electrodes and samples as discussed before. The initial resistivity of LSS-SH mixes increased with an increase in alkali content (Fig. 5,c), which was not expected as the increase in alkali content should decrease the resistivity of the AAFA concrete as the concentration of ions in the paste increased. The observed increase in the resistivity from LSS-SH-8 to LSS-SH-12 could be caused by the higher water content in 
mixes containing more alkalis (Table 3). The resistivity of LSS-SH mixes did however equalize by the end of the heating phase (Fig. 5,c).

The calculated temperature coefficients of AAFA cement pastes ( $\alpha$, Table 5) are considerably higher than the value of $0.022 /{ }^{\circ} \mathrm{C}$ found by Whittington et al. (1981) for Portland cement paste. Alkali-activated fly ash cement pastes appear to be much more sensitive to temperature in comparison to Portland cement paste, especially when activated with sodium silicate solution (LSS-9, LSS-SH, Table 5). The higher temperature coefficient indicates that AAFA cement paste drops its resistivity faster than Portland cement paste, which will positively affect power consumption during DEC. The drop in resistivity is caused by an increased degree of hydrolysis of electrolytes with an increase in temperature. Additionally, the mobility of sodium ions in the sodium silicate solution significantly increases with temperature rise. These two factors could be responsible for the significant drop in the resistivity of AAFA cement pastes containing sodium silicates.

\subsection{Compressive strength}

Compressive strength results are presented in Fig. 6 and 7.

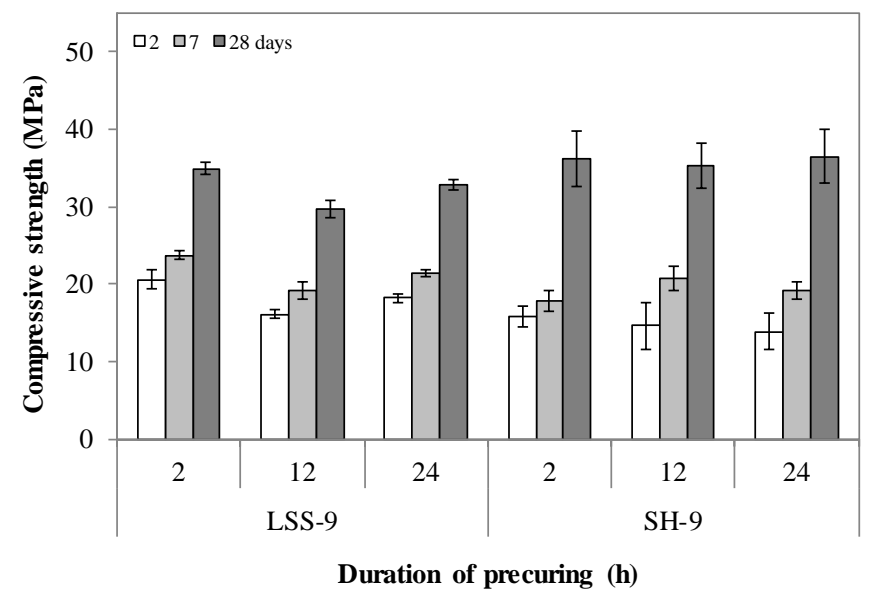

Fig. 6. Effect of duration of precuring on compressive strength development of LSS-9 and SH-9 mixes. 


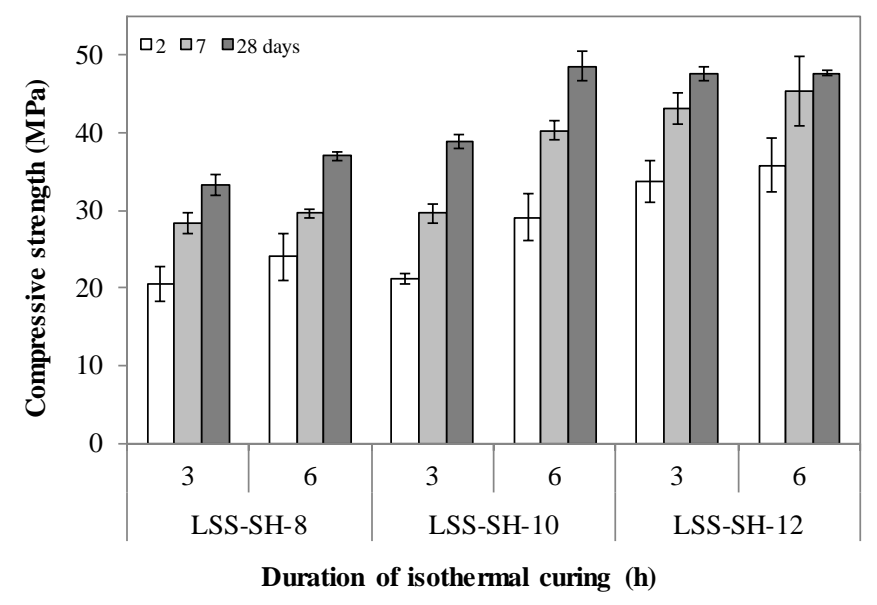

Fig. 7. Effect of duration of isothermal curing on compressive strength development of LSSSH mixes.

Shekhovtsova et al. (2014) found that AAFA cement pastes with similar composition to the composition of SH-9 could hardly be demoulded after 7 days and had a compressive strength of only 10.9 MPa at 28 days when cured at $25^{\circ} \mathrm{C}$. Results of Somna et al. (2011) confirms that the strength development of AAFA cement pastes is very slow at ambient temperature. As can be seen from Fig. 6, DEC significantly improved the strength performance in comparison to ambient temperature curing. The compressive strength at 2 and 28 days was in the range of 15 and $36 \mathrm{MPa}$ respectively.

The duration of the precuring affected the compressive strength development of AAFA concretes activated with sodium silicate (LSS-9, Fig. 6). Two hours precuring gave the best results as the compressive strength was the highest at all ages. In contrast, the duration of precuring did not have a significant effect on strength of AAFA concretes activated with sodium hydroxide, especially at 28 days ( $\mathrm{SH}-9$, Fig. 6), but the difference in maximum curing temperature reached by SH-9 mix precured for 2, 12 and 24 hours have to be noted (Fig. 4). The difference in compressive strength of SH-9 mix at 2 days was probably caused by the 
fact that the mix precured for 2 hours reached $60{ }^{\circ} \mathrm{C}$, where mixes precured for 12 and 24 hours were heated to about $45^{\circ} \mathrm{C}$ (Fig. 4).

During the second stage of the experiment, 2 hours precuring was selected for LSS-SH mixes as it gave the best strength performance during the first stage. Additionally, long precuring times are not always practical, and an increase in precuring time can lead to an increase in the resistivity of AAFA concrete mix (SH-9, Table 5) which would cause increased power consumption during DEC.

The decrease in duration of isothermal curing from 6 to 3 hours negatively influenced the compressive strength of LSS-SH-8 and LSS-SH-10 mixes (Fig. 7). LSS-SH-10 mix lost the most from the decreased curing time as the compressive strength at 28 days decreased by 20\%. In contrast, the duration of isothermal curing does not significantly affect the compressive strength of the LSS-SH-12 mix. Comparing the 28-d compressive strength of the LSS-SH mixes, which were isothermally cured for 6 hours (Fig. 7), it can be seen that the LSS-SH-10 mix gained the highest strength, which correlates with results found by Shekhovtsova et al. (2014), indicating that there is an optimal alkali content in AAFA cements and excessive amounts of alkali negatively affects mechanical properties of the material. However, the compressive strength of LSS-SH mixes isothermally cured for 3 hours increased with increase in alkali content (Fig. 7). It can be suggested that alkali content should be increased above the optimal concentration if AAFA concretes would be cured for short time without resulting in a considerable drop in target compressive strength.

The relatively high standard deviation in strength of SH-9 mix should be noted (Fig. 6). Strength deviation of AAFA concretes containing sodium hydroxide and sodium silicate (LSS-SH, Fig. 7) is relatively high during the early stage of hardening (2 and 7 days) and reduces at 28 days in comparison to the concretes activated with sodium hydroxide ( $\mathrm{SH}-9$, Fig. 6). LSS-9 mixes have a low standard deviation at all ages (Fig. 6). The high standard 
deviation in the compressive strength of SH-9 mixes could be caused by the insufficient heat curing as discussed before (Fig. 4).

It is interesting to note that the 28-d compressive strength of $\mathrm{SH}-9$ mixes at $36 \mathrm{MPa}$ is higher than that of LSS-9 mixes at 32 MPa despite the improper curing of SH-9 mixes (Fig. 6), which is unexpected as AAFA concretes containing sodium silicate normally have a higher compressive strength in comparison to fly ash concretes activated with sodium hydroxide (Fernández-Jiménez and Palomo, 2005; Palomo et al., 1999; Shekhovtsova, 2015). The results therefore show that DEC has a good potential for producing fly ash concretes activated with sodium hydroxide, which might be economically beneficial as these concretes normally have significantly lower material cost in comparison to AAFA concretes containing sodium silicates (McLellan et al., 2011). Additionally, AAFA concrete mixes containing only sodium hydroxide might be "greener" (i.e., having lower environmental effect) than mixes activated with sodium silicate solutions (Habert et al., 2011).

Despite the higher water-to-binder solids ratio, LSS-SH mixes had significantly higher compressive strength in comparison to LSS-9 and SH-9 mixes (Fig. 6-7). Sodium silicates with an optimized silica modulus provide better strength development of AAFA cements (Criado et al., 2005). Short isothermal curing for 3 hours provides relatively high compressive strength up to $33.8 \mathrm{MPa}$ at 2 days and $48.5 \mathrm{MPa}$ at 28 days (LSS-SH-12, Fig. 7), indicating that DEC can be effectively used for production of AAFA concretes.

\section{Conclusions}

In this study, low calcium fly ash, sodium hydroxide, and sodium silicate were used to produce alkali-activated fly ash concretes subjected to direct electric curing at $60{ }^{\circ} \mathrm{C}$. The following conclusions can be drawn from the investigation.

The resistivity of alkali-activated fly ash cement paste strongly depends on the type of activator used. Sodium hydroxide gives significantly lower resistivity $(0.16-0.39 \Omega \bullet m)$ than 
sodium silicates $(0.31-0.51 \Omega \bullet \mathrm{m})$. The resistivity of Portland cement paste is considerably higher at $2.2 \Omega \bullet \mathrm{m}$ indicating that less energy is needed for direct electric curing of alkaliactivated fly ash concretes.

Electric resistivity of the alkali-activated fly ash concretes is more sensitive to temperature in comparison to the resistivity of Portland cement concretes, especially when sodium silicates are used as activators. Temperature coefficients up to $0.119 /{ }^{\circ} \mathrm{C}$ were found for alkali-activated fly ash concretes in comparison to $0.022 /{ }^{\circ} \mathrm{C}$ for Portland cement concrete found in literature. The results show that the resistivity of alkali-activated fly ash concretes decreases faster with increase in temperature than that of Portland cement concrete, which will positively affect power consumption during direct electric curing.

Short precuring times are suggested because they result in higher compressive strength for alkali-activated fly ash concretes, and power consumption can be potentially reduced as the resistivity of fly ash concrete activated with sodium hydroxide increases with time.

Compressive strengths up to $33.8 \mathrm{MPa}$ and $48.5 \mathrm{MPa}$ at 2 and 28 days respectively can be achieved after relatively short direct electric curing (2 hours of heating and 3 hours of isothermal curing, which can be implemented during off-peak hours). Alkali-activated fly ash cements of similar composition cured at ambient temperature achieve compressive strength of 10.9 MPa at 28 days.

Alkali-activated fly ash concretes showed very good response to direct electric curing developing high compressive strength which opens new opportunities for much wider in-situ use of alkali-activated fly ash concretes resulting in more extensive utilization of unclassified low calcium fly ash in the construction industry.

\section{Acknowledgements}


The authors would like to thank Krak Electrical, CC for sponsoring the electric curing rig and Lisa Jansen van Rensburg for valuable experimental data. Editorial input of Alan Hall is gratefully acknowledged.

\section{References}

Abdalqader AF, Jin F, Al-Tabbaa A. Development of greener alkali-activated cement: utilisation of sodium carbonate for activating slag and fly ash mixtures. J Clean Prod 2015;113: 66-75. doi:10.1016/j.jclepro.2015.12.010

Bakharev T. Geopolymeric materials prepared using Class F fly ash and elevated temperature curing. Cem Concr Res 2005;35(6):1224-32. doi:10.1016/j.cemconres.2004.06.031

Bredenkamp S, Kruger D, Bredenkamp GL. Direct electric curing of concrete. Mag Concr Res 1993;45(162):71-74. doi:10.1680/macr.1993.45.162.71

BS EN 12390-3. Testing hardened concrete - Part 3: Compressive strength of test specimens, United Kingdom: British Standards Institution.

Chindaprasirt P, Rattanasak U, Taebuanhuad S. Role of microwave radiation in curing the fly ash geopolymer. Adv Powder Technol 2013;24(3):703-7. doi:10.1016/j.apt.2012.12.005

Criado M, Fernández-Jiménez A, Palomo A. Alkali activation of fly ash. Part III: Effect of curing condition on reaction and its graphical description. Fuel 2010;89(11):3185-92. doi:10.1016/j.fuel.2010.03.051

Criado M, Palomo A, Fernández-Jiménez A. Alkali activation of fly ashes. Part 1: Effect of curing conditions on the carbonation of the reaction products. Fuel 2005;84(16):2048-54. doi:10.1016/j.fuel.2005.03.030

Diaz EI, Allouche EN, Eklund S. Factors affecting the suitability of fly ash as source material for geopolymers. Fuel 2010;89(5):992-96. doi:10.1016/j.fuel.2009.09.012

Diop MB, Grutzeck MW. Low temperature process to create brick. Constr Build Mater, 2008;22(6):1114-21. doi:10.1016/j.conbuildmat.2007.03.004 
Eskom Integrated Report 2014, viewed 08 July 2015, $<$ http://integratedreport.eskom.co.za/pdf/full-integrated.pdf $>$.

Fernández-Jiménez A, de la Torre AG, Palomo A, López-Olmo G, Alonso MM, Aranda MAG. Quantitative determination of phases in the alkali activation of fly ash. Part I. Potential ash reactivity. Fuel 2006a;85(5-6):625-34. doi:10.1016/j.fuel.2005.08.014

Fernández-Jiménez A, de la Torre AG, Palomo A, López-Olmo G, Alonso MM, Aranda MAG. Quantitative determination of phases in the alkaline activation of fly ash. Part II: Degree of reaction. Fuel 2006b;85(14-15):1960-69. doi:10.1016/j.fuel.2006.04.006

Fernández-Jiménez A, Palomo A. Characterization of fly ashes. Potential reactivity as alkaline cements. Fuel 2003;82(18):2259-65. doi:10.1016/S0016-2361(03)00194-7

Fernández-Jiménez A, Palomo A. Composition and microstructure of alkali activated fly ash binder: Effect of the activator. Cem Concr Res 2005;35(10):1984-92. doi:10.1016/j.cemconres.2005.03.003

Habert G, d'Espinose de Lacaillerie JB, Roussel N. An environmental evaluation of geopolymer based concrete production: reviewing current research trends. J Clean Prod 2011;19(11):1229-38. doi:10.1016/j.jclepro.2011.03.012

Hardjito D, Rangan BV. Development and properties of low-calcium fly ash-based geopolymer concrete: research report GC 1. Faculty of Engineering, Curtin University of Technology, Perth, Australia; 2005.

He J, Jie Y, Zhang J, Yu Y, Zhang G. Synthesis and characterization of red mud and rice husk ash-based geopolymer composites. Cem Concr Compos 2013;37(1):108-18. doi:10.1016/j.cemconcomp.2012.11.010

Heath A, Paine K, McManus M. Minimising the global warming potential of clay based geopolymers. J Clean Prod 2014;78:75-83. doi:10.1016/j.jclepro.2014.04.046

Heritage I, Khalaf FM, Wilson JG. Thermal acceleration of Portland cement cement concretes using direct electronic curing. ACI Struct J 2000;97(1):37-40. doi:10.14359/803 
Kajaste R, Hurme M. Cement industry greenhouse gas emissions - management options and abatement cost. J Clean Prod 2015;112:4041-4052. doi:10.1016/j.jclepro.2015.07.055

Kovalchuk G, Fernandez-Jimenez A, Palomo A. Alkali-activated fly ash: Effect of thermal curing conditions on mechanical and microstructural development - Part II. Fuel 2007;86(3):315-22. doi:10.1016/j.fuel.2006.07.010

Kovtun M, Shekhovtsova J, Kearsley EP. Direct electric curing of alkali-activated concretes. Preliminary study. Concrete 2015. Proceedings of the 27th Biennial National Conference of the Concrete Institute of Australia in conjunction with the 69th RILEM Week "Construction Innovations, Research into Practice”, 30 August - 2 September 2015, Melbourne, Australia, $1116-24$.

Longhi MA, Rodríguez ED, Bernal SA, Provis JL, Kirchheim AP. Valorisation of a kaolin mining waste for the production of geopolymers. J Clean Prod 2015;115:265-272. doi:10.1016/j.jclepro.2015.12.011

Matjie RH, Ginster M, van Alphen C, Sobiecki A. Detailed characterisation of Sasol ashes. In: World of Coal Ash (WOCA). Lexington, Kentucky, USA, April 11-15, 2005.

McLellan BC, Williams RP, Lay J, van Riessen A, Corder GD. Costs and carbon emissions for geopolymer pastes in comparison to ordinary Portland cement cement. J Clean Prod 2011;19(9-10):1080-90. doi:10.1016/j.jclepro.2011.02.010

Mejía JM, de Gutiérrez RM, Montes C. Rice husk ash and spent diatomaceous earth as a source of silica to fabricate a geopolymeric binary binder. J Clean Prod 2016;118:133-139. doi:10.1016/j.jclepro.2016.01.057

Neville AM. Properties of concrete. 4th ed. Harlow: Longman; 1995.

Nimwinya E, Arjharn W, Horpibulsuk S, Phoo-ngernkham T, Poowancum A. A sustainable calcined water treatment sludge and rice husk ash geopolymer. J Clean Prod 2016;119:128134. doi:10.1016/j.jclepro.2016.01.060 
Palomo A, Grutzeck MW, Blanco MT. Alkali-activated fly ashes A cement for the future. Cem Concr Res 1999;29(8):1323-29. doi:10.1016/S0008-8846(98)00243-9

Puertas F, Martínez-Ramírez S, Alonso S, Vázquez T. Alkali-activated fly ash/slag cements: Strength behavior and hydration products. Cem Concr Res 2000;30(10):1625-32. doi:10.1016/S0008-8846(00)00298-2

Ravikumar D, Peethamparan S, Neithalath N. Structure and strength of $\mathrm{NaOH}$ activated concretes containing fly ash or GGBFS as the sole binder. Cem Concr Compos 2010;32(6):399-410. doi:10.1016/j.cemconcomp.2010.03.007

Shekhovtsova J, Kearsley EP, Kovtun M. Effect of activator dosage, water to binder solids ratio, temperature and duration of elevated temperature curing on the compressive strength of alkali-activated fly ash paste. J S Afr Inst Civ Eng 2014;56(3):44-52.

Shekhovtsova J. Using South African fly ash as a component of alkali-activated binder: PhD dissertation. Faculty of Engineering, Built Environment \& IT, University of Pretoria, Pretoria, South Africa; 2015.

Somaratna J, Ravikumar D, Neithalath N. Response of alkali activated fly ash mortars to microwave curing. Cem Concr Res 2010;40(12):1688-96. doi:10.1016/j.cemconres.2010.08.010

Somna K, Jaturapitakkul C, Kajitvichyanukul P, Chindaprasirt P. NaOH-activated ground fly ash geopolymer cured at ambient temperature. Fuel 2011;90(6):2118-24. doi:10.1016/j.fuel.2011.01.018

Torres-Carrasco M, Puertas F. Waste glass in the geopolymer preparation. Mechanical and microstructural characterisation. J Clean Prod 2015;90:397-408. doi:10.1016/j.jclepro.2014.11.074

Van Deventer JSJ, Provis JL, Duxson P, Brice DG. Chemical research and climate change as drivers in the commercial adoption of alkali activated materials. Waste Biomass Valorization 2010;1(1):145-55. doi:10.1007/s12649-010-9015-9 
Van Deventer JSJ, Provis JL, Duxson P. Technical and commercial progress in the adoption of geopolymer cement. Miner Eng 2012;29:89-104. doi:10.1016/j.mineng.2011.09.009 Van Riessen A, Chen-Tan N. Beneficiation of Collie fly ash for synthesis of geopolymer Part 2 - Geopolymers. Fuel 2013a;111(September):829-35. doi:10.1016/j.fuel.2013.04.015

Van Riessen A, Chen-Tan N. Beneficiation of Collie fly ash for synthesis of geopolymer: Part 1 - Beneficiation. Fuel 2013b;106(April):569-75. doi:10.1016/j.fuel.2012.11.070

Wadhwa SS, Srivastava LK, Gautam DK, Chandra D. Direct electric curing of in-situ concrete. Batim Int Build Res Pract 1987;20(2):97-101. doi:10.1080/09613218708726799 Ward CR, French D. Determination of glass content and estimation of glass composition in fly ash using quantitative X-ray diffractometry. Fuel 2006;85(16 spec. iss.):2268-77. doi:10.1016/j.fuel.2005.12.026

Whittington HW, McCarter J, Forde MC. The conduction of electricity through concrete. Mag Concr Res 1981;33(114):48-60. doi:10.1680/macr.1981.33.114.48

Wilson JG, Gupta NK. Equipment for the investigation of the accelerated curing of concrete using direct electrical conduction. Measurement 2004;35(3):243-50. doi:10.1016/j.measurement.2003.11.002

Yang $\mathrm{KH}$, Song JK, Song KI. Assessment of $\mathrm{CO}_{2}$ reduction of alkali-activated concrete. J Clean Prod 2013;39:265-72. doi:10.1016/j.jclepro.2012.08.001 